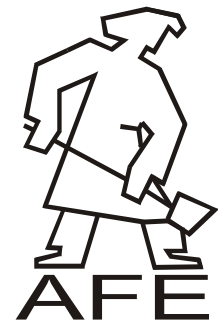

\title{
Analysis and Assessment of Measurements Results of Electric Power Demand in a Model Vacuum-assisted Moulding Installation
}

\author{
K. Smyksy*, R. Wrona, M. Brzeziński, E. Ziółkowski \\ AGH, Faculty of Foundry Engineering, Department of Foundry Processes Engineering, \\ Reymonta 23, 30-059 Krakow, Poland \\ * Corresponding author. E-mail address: ksmyksy@agh.edu.pl
}

Received 04.07.2012; accepted in revised form 03.09.2012

\begin{abstract}
In this article the main problems related with the proper choice of the design and operation parameters of vacuum installation in vacuum moulding system have been discussed. In such system a vacuum are generated using electric-driven vacuum pumps. The aim of the experiment is to evaluate the performance of a vacuum system basing on registered plots of selected electric power parameters of the power-supplying system of the pumps with parallel measurements instantaneous values of pressure in selected points of model stand. The measurements system for power-supply unit has incorporated the recorders of instantaneous current and voltage values. Following the suitable numerical procedure, the experimental data are analysed to yield mathematical relationships between the variations of the generated vacuum pressure levels and variations of selected electric power parameters. According to the authors, the applied measurements system of the parameters of a vacuum-assisted installation may become an effective and easy practical method of evaluating the performance of such installations, used also in industry.
\end{abstract}

Keywords: Mechanisation and automation of foundry processes, Electric power measurements, Vacuum-assisted moulding processes

\section{Introduction}

The complex assessment of the operation of the foundry machines is very complicated problem. The main evaluation criterion of machine operation is the best realization of technological process. But in many foundry process the area of admissible parameters can be relatively large. In this case the additional criterion of assessment may be useful. One of such criterion may be energy-efficiency of the machine operation. It has influenced on running costs of the machine and has also special meaning from ecological point of view.
The best solution for evaluating proper operation parameters of the machine with electric drive is the parallel measurements of physical values influenced on the process run and values characterizing the electrical parameters of the drive. Such attitude demands great experiences in foundry machine investigating and also the using of modern advanced measurements technique.

Besides the cognitive function of such measurements they can be useful in monitoring of foundry operations executed by machines in foundry plants- the important question in supervision, control and regulation procedures of modern machines and installations [1, 2, 3, 4]. Such systems and their respective 
components experience variable loads whilst in service. Under variable loading the functional and performance parameters of machines will change and processes taking place in installations involving several structural components may undergo some changes as well. The quantitative evaluation of applied loading is the field of reliability testing. The research data should include the specification data and parameters quoted by manufacturers of foundry equipment and by specialised organisational units within the foundry plants. Reliability and accuracy of the supplied data depend on the actual criteria adopted for the assessment of the condition of the process or system. In the test procedure we have operational parameters at the input and performance parameters at the output, associated with the machine or process conditions. It is readily apparent that some of these quantities are obtained from measurements requiring specialised methods to derive their operational characteristics. The measurement of relevant energy parameters seems most reliable in these applications $[5,6,7,8]$.

The vacuum technology is widely used in foundry industry [9, 10]. The information about it is present in various forms available on the Internet [11]. In the area of moulding process the most known is $\mathrm{V}$ process, still in use in may foundry plant. In green sand technology is well known the Vacupress machines of Künkel Wagner Company, HFM of Haflinger GmbH or vacuum module in Disamatic [10]. The key problem of vacuum moulding is the proper choice of vacuum installation parameters. The two main parameters of vacuum installation are the pump system capacity and the power of pump drive. The typical relations between power of vacuum pump drive and pump capacity in logarithmic coordinate is almost linear- Fig. 1.

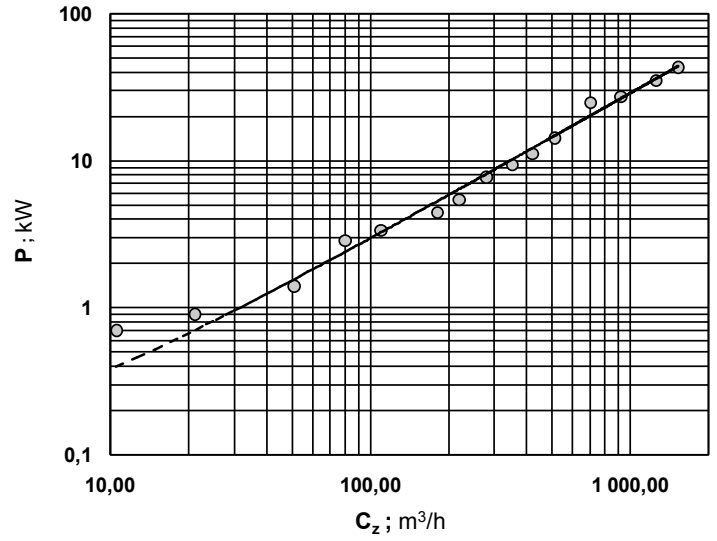

Fig. 1. Dependence between drive active power- $\mathbf{P}$ and vacuum pump capacity- $\mathbf{C}_{\mathbf{z}}$ (sucked air at $213 \mathrm{hPa}$ ). Series of vacuum pumps - PW of Hydro-Vacuum S.A. (data from [12])

The increasing the capacity output of the pump is of course connected with increasing of power drive. But the suction of air unit from vacuum tank can be connected with different energy demand. It is visible from Fig. 2 that for a given pump series the energy factor (ratio of drive power to capacity of pump) is, in majority, more profitable for larger devices. This factors is influenced also by the type of the pump, what is evident from data inserted in Tab. 1.

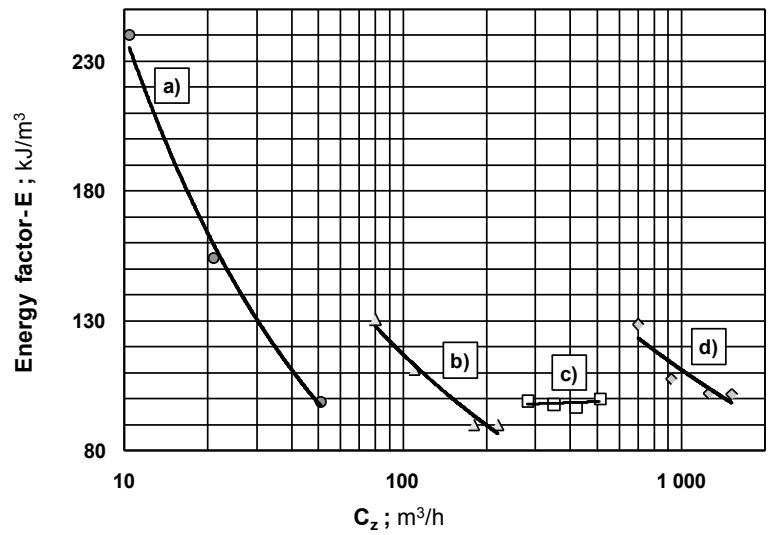

Fig. 2. Dependence between energy factor- $\mathbf{E}$ and vacuum pump capacity- $\mathbf{C}_{\mathbf{z}}$ (sucked air at $213 \mathrm{hPa}$ ). Series of vacuum pumps - PW of Hydro-Vacuum S.A.: a) PW.1, b) PW.4, c) PW.5, d) PW.7 (data from [12])

Table 1 .

The characterization of selected vacuum-pumps of Oerlikon Leybold Vacuum GmbH - data from [12]

\begin{tabular}{|c|c|c|c|c|}
\hline pump type & $\begin{array}{c}\text { Capacity } \\
-\mathbf{C}_{\mathbf{z}} \\
\mathbf{m}^{3} / \mathbf{h}\end{array}$ & $\begin{array}{c}\text { Range of } \\
\text { pressure } \\
-\mathbf{P}_{\mathrm{z}}, \\
\text { mbar }\end{array}$ & $\begin{array}{c}\text { Power } \\
\text { of } \\
\text { drive- } \\
\text { P, } \\
\text { kW }\end{array}$ & $\begin{array}{c}\text { Energy } \\
\text { factor- } \\
\mathbf{E}^{*}, \\
\mathbf{k J} / \mathbf{m}^{3}\end{array}$ \\
\hline $\begin{array}{l}\text { SCREWLINE SP } \\
250, \text { screw }\end{array}$ & 270 & $<2 * 10^{-1}$ & 7,5 & 100 \\
\hline $\begin{array}{l}\text { SOGEVAC SV } 300 \\
\text { B, rotary vane } \\
\text { with liquid ring }\end{array}$ & 240 & $<8 * 10^{-2}$ & 5,5 & 82,5 \\
\hline $\begin{array}{l}\text { RUVAC WA 251, } \\
\text { Roots }\end{array}$ & 210 & $<8 * 10^{-4}$ & 1,1 & 18,9 \\
\hline
\end{tabular}

The data from folders can be only treated as rough estimation of energy consumption of pump drive. The precisely evaluation of energy factors demands the measurements of electric parameters of drive during the whole operation cycle of vacuum installation parameters. The connection of such measurements results with measurements results of another technical parameters characterising the machine operation makes possible the real assessment of device operation

\section{Description of the measurement method and tests facility}

In the investigated variant of vacuum-assisted moulding process there is no transport of the moulding sand from the hopper to the technological space, as in the known another methods $[13,14,15]$. The moulding sand is gravitational dosed to the moulding chamber. The aeration of moulding sand is profitable for better compaction results. The air stream action on moulding sand is due to quick connection of the space beneath pattern plate (with vents) with vacuum tank. The compaction level in this method are much worse than in another air-stream 
moulding method [10]. High tightness of technological space is not required. The compaction distribution in pattern pockets is very advantageous and sufficient for obtainment the high level of compaction in the next step of moulding- squeezing. The proper run of this process demands adequate choice of vacuum tank volume ( in relation to the volume of moulding chamber), value of pressure in vacuum tank, open area of vents, open area of impulse valve and its opening time. Selection of the parameters of vacuum pump system is decisive for energy-efficiency of this moulding method.

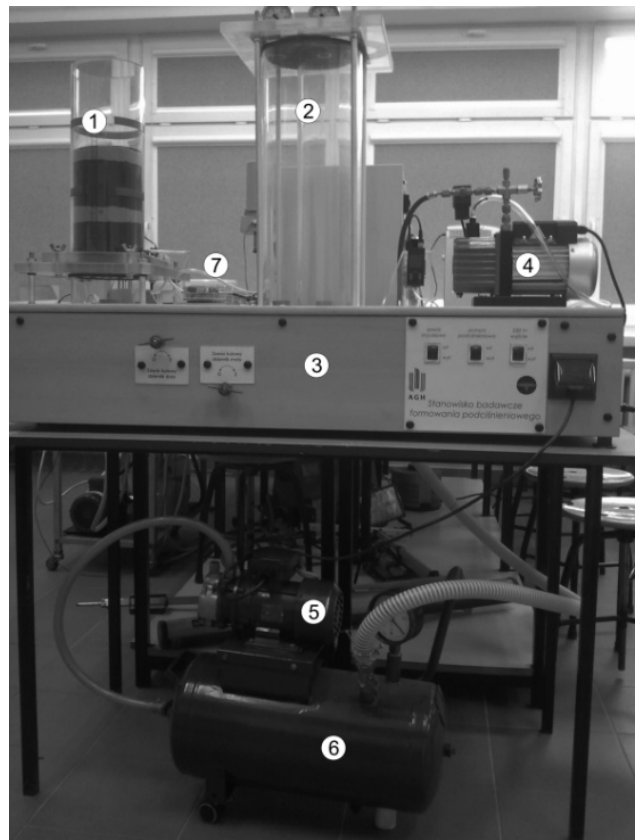

Fig. 3. Model stand for investigating vacuum moulding installations

[14]: 1- moulding chamber, 2- vacuum tank, 3- control unit, 4- vacuum pump No. 1, 5- vacuum pump No. 2, 6- additional vacuum tank, 7- pressure transducers

The model test stand (presented on Fig. 3) was constructed by analogy to solutions used in industry. It is incorporating the following systems: a vacuum installation system with pumps and tanks, moulding chamber, pressure measurement system in the vacuum installation with data recording system. As a vacuum source two vacuum pumps with the power ratings $0.18 \mathrm{~kW}$ each, connected to the moulding chamber via electromagnetic valves has been used. Vacuum internal tank of the stand comprising two cylinders 110 and $190 \mathrm{~mm}$ in diameter and having the volume $\mathrm{V}_{\mathrm{a}}=4.75 \mathrm{dm}^{3}$ and $\mathrm{V}_{\mathrm{b}}=9.42 \mathrm{dm}^{3}$. There is a possibilities of connection of external vacuum tank of $24 \mathrm{dm}^{3}$ volume. Respective connection of internal and external tanks has created two volumes used in tests: $V_{1}=28.75 \mathrm{dm}^{3}$ and $V_{2}=38.17 \mathrm{dm}^{3}$. These components are connected with a pipe installation and ball valves WKK4a. This configuration allows for extending the scope of the experimental program, so the influence of the chamber volume on the compaction performance can be investigated (Fig. 3) $[13,14,15]$.

The circuit for measuring the vacuum levels comprises four differential pressure transducers MPX2100, manufactured by
Motorola. Analogue signals are further amplified by signal amplifiers MC33272A. Pressure transducers are connected to the vacuum installation via an elastic pipe conduit and are located at four points: the vacuum installation under the impulse valve, the chamber under the pattern plate, the internal vacuum tank, the moulding chamber. Such configuration allows the pressures to be registered at the key points of the installation. The recording system incorporates a microprocessor-based digital recorder. This configuration ensures most accurate recording of analogue data from the measurement circuit. Data are sampled at the frequency $300 \mathrm{~Hz}$ for each transducer system. The recorder has a number of extensions and seats to enable the remote-control activation of the recording process and real-time data transmission to the computer via the RS232 and USB ports, at variable speed of data transfer $[8,13]$.

During the tests the measurements of electric power parameters are also taken with another measurement system incorporating a prototype recorder of instantaneous current and voltage levels - Fig. 4.

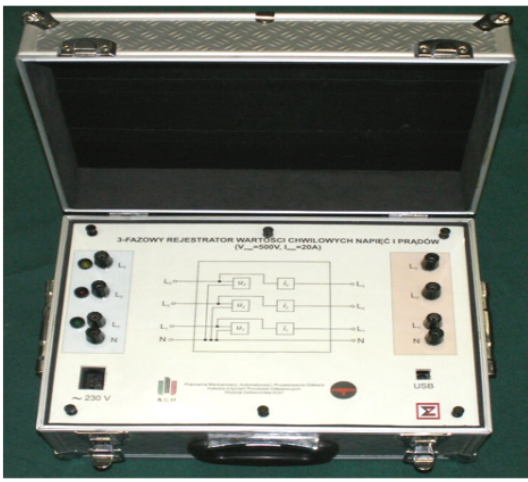

Fig. 4. Recorder of instantaneous values of voltage and current signals- general view

This system was developed at the Chair of Mechanisation, Automation and Design of Foundries at the Faculty of Foundry Engineering, AGH UST [among others 4, 8, 16]. The measurement system incorporates a processor CS5451A (Cirrus Logic) having six channels with 24 bit resolution. These channels are used for measuring instantaneous voltage and current levels in each phase of the three-phase installation power-supplying the investigated foundry machines. The recorder executes 4000 measurements per second, concurrently in each of the six channels. Recorded data are transmitted to the computer via a USB interface (version 2.0). Besides, the newly designed recorder enables the measurements to be taken in foundry machines powered directly from the mains or via inverter systems. The operation of the instantaneous voltage and current recorder is supported by the computer program developed by the authors. The program establishes the computer-recorder connection, stores the measurement data in its memory, generates visualised plots of instantaneous current and voltage and power levels and executes the scheduled calculations of other electric power parameters using the digital data processing algorithms. Since the DSP algorithms in the dedicated computer program can be selected, we get a predetermined number of measured RMS values per second, which is a major advantage of this method over conventional measurement systems. Based on the registered voltage and current 
levels, the following electric power parameters can be determined: RMS voltage and current levels in each phase, active, reactive and apparent power levels, power coefficients $\cos \varphi$ and $\tan \varphi$, fundamental frequency for the selected run of voltage or current. All measured signals and those derived by the computer program can be saved and exported to other programs, such as spreadsheets. A major advantage of the recorder is that it can be incorporated in the circuits supplying inverter-controlled electric motors. This feature is unavailable in many commercial systems for power measurements in electric power installations.

The usefulness of power measurements in monitoring of foundry process is demonstrated by testing done on selected machines. So far the method and the measurement equipment has been tested when investigating the mixing processes in paddle, roller and rotary foundry mixers $[4,16,17]$ and also in test of vacuum assisted moulding installation [13].

\section{Measurements results}

The experimental program involves the measurements of electric power parameters whilst the vacuum is being generated in the installation connected to one or two pumps. The vacuum installation comprises two chambers differing in volume $\left(\mathrm{V}_{1}\right.$ and $\left.\mathrm{V}_{2}\right)$. Since the installation is equipped with two vacuum pumps, measurements can be taken in various configurations: pump 1, pump 2 and for two pumps operated concurrently. Exemplary plots of instantaneous values of

a)

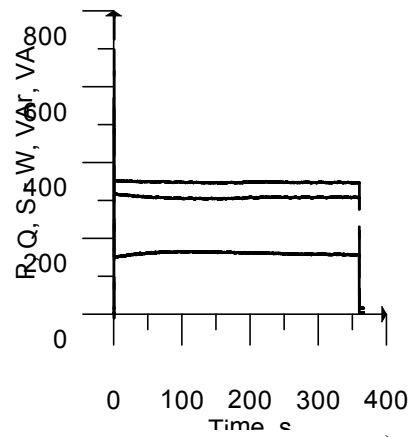

d)

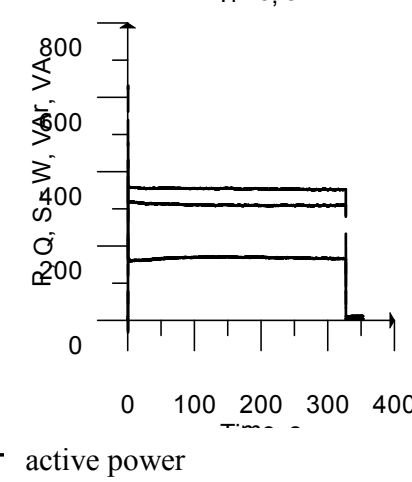

b)
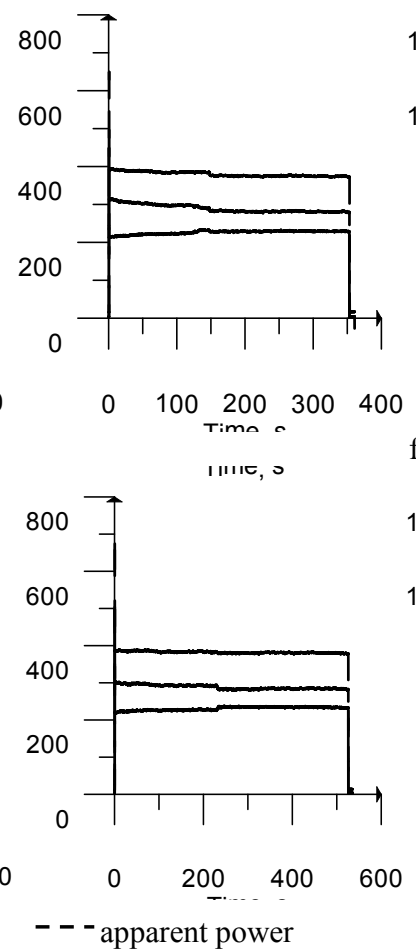

current, voltage and instantaneous power are shown in Fig 5. Registered graphs deviate from the current intensity plots in the supply system, revealing large levels of instantaneous power at the instant the supplying system is activated to power the two pumps. That suggests the necessity to use the noise filtering systems as well as protective elements in the electric supply systems. Large levels of instantaneous power registered at the instant when the supply system is switched on are also revealed on plots of active power and the generated vacuum levels (Fig. 7). The maximal active power at the instant the supply system is switched on is decidedly larger than power uptake by the pump in the phase of its stable operation.

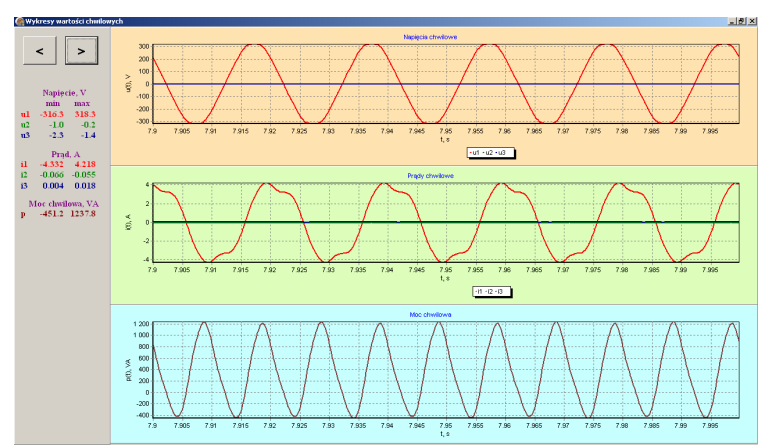

Fig. 5. Exemplary registered plots of instantaneous voltage and current intensity levels during the steady-state operation of the two pumps.

c)

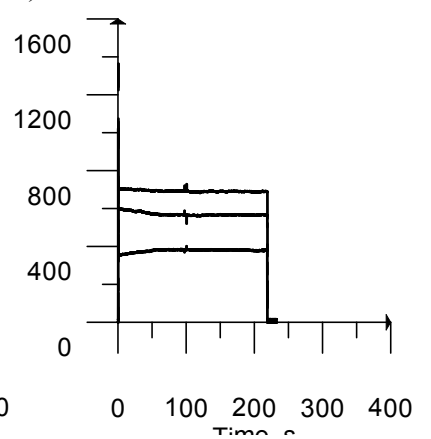

f)

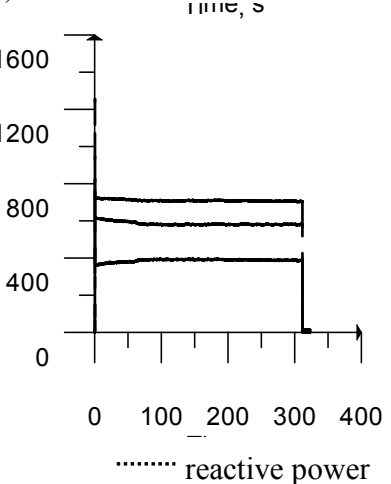

Fig. 6. Power signals registered in the course of the first stage of vacuum-assisted process: a- pump No.1, tank volume- $V_{1}$, b- pump No.2, tank volume- $V_{1}$, c- pump No.1 and No.2, tank volume- $V_{1}$, d- pump No. 1 , tank volume- $V_{2}$, e- pump No. 2, tank volume- $V_{2}$, f- pump No.1 and No.2, tank volume- $V_{2}$ 
It is apparent (see Fig. 7) that the variation of the vacuum level causes a change of the active power uptake by the vacuum pump. In the investigated time period, the active power level changes from about 8 to $9 \%$. The measured values of active power during emptying period of tanks is different from nominal value of drive power. It concerns both pump, but for pump No. 1 the measured value is lower than nominal value and for pump No. 2 is greater. a)

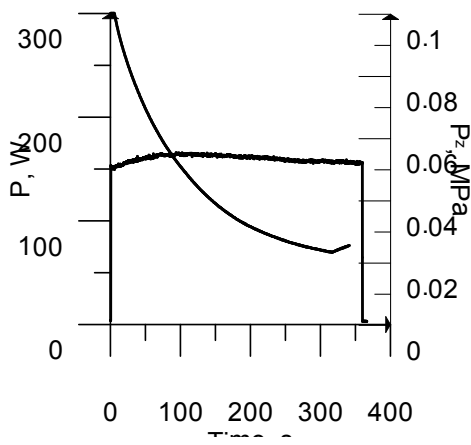

d)

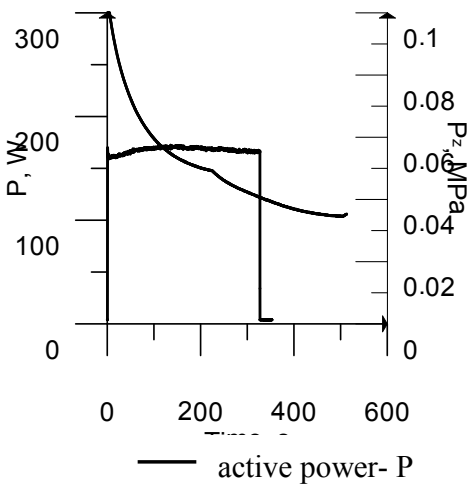

b)

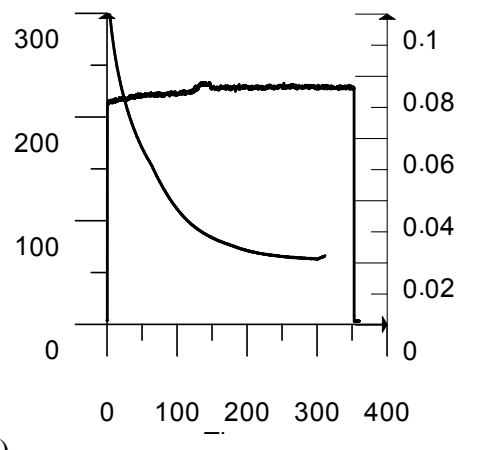

e)

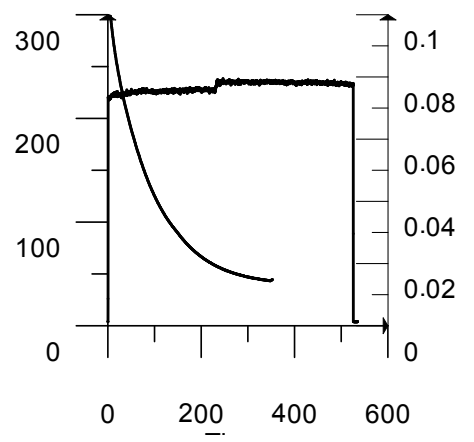

c)

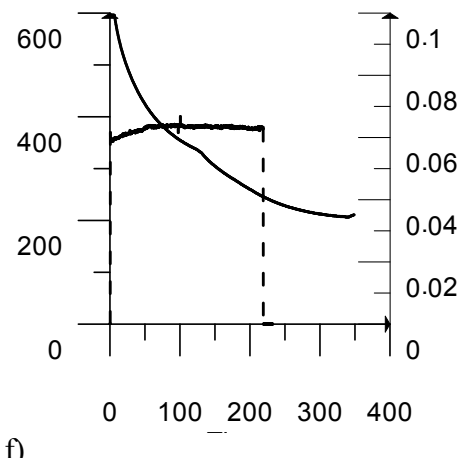

f)

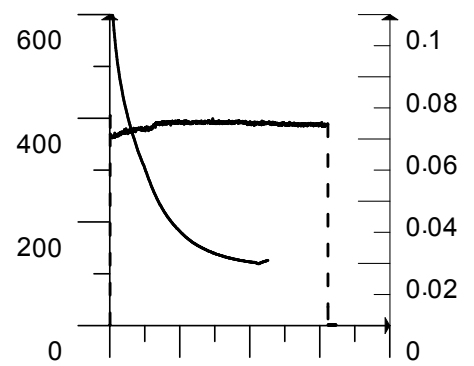

$0 \quad 100 \quad 200 \quad 300 \quad 400$

- - - absolute pressure in vacuum tank- $\mathrm{P}_{\mathrm{z}}$

Fig. 7. Time run of active power and absolute pressure in vacuum tank signals registered in the course of the first stage of vacuum-assisted process: a- pump No. 1 , tank volume- $V_{1}$, b- pump No. 2 , tank volume- $V_{1}$, c- pump No. 1 and No. 2 , tank volume- $V_{1}$,

d- pump No. 1, tank volume- $V_{2}$, e- pump No. 2, tank volume- $V_{2}$, f- pump No. 1 and No. 2 , tank volume- $V_{2}$

Fig. 7 shows the plot of active power registered when vacuum pressure is generated in the supply system, for each pump separately and for two pumps operating concurrently. It can be easily seen that the loading characteristic of the pump 2 changes significantly when a certain level of vacuum pressure is achieved. In the case of the pump 1, this phenomenon is not observed. Though both pumps are single-stage pumps, their operational characteristics will differ, these differences being attributable to their design features and the level of wear and tear. From the Fig. 7 one can see that besides the same values of the nominal power the capacity of the pump are differ. There are different time for achievement the same level of pressure.

The significant change of active power at the first period of tank emptying (Fig. 7) allows for monitoring the vacuum generation process, supported by dedicated algorithms. The correlation between pressure value and active power (elaborated data from time runs- Fig. 7) is undoubtful for a given tank volume- Fig. 8 .

The analysis of measurements of electric parameters can also give the precise answer about process duration. Fig. 9 shows the typical relations between the initial pressure in vacuum tank and the obtained quality of the compacted mould. It is apparent (see Fig. 9) that decreasing of the initial values of pressure in vacuum tank (beneath 0.04 $\mathrm{MPa}$ ) does not lead to significant improvement of density and hardness of the mould, but as it is seen on Fig. 7 decreasing the pressure to the
$0.02 \mathrm{MPa}$ needs much more time and consequently the higher energy demand (than to the $0.04 \mathrm{MPa}$ value). Of course, the more precise analysis needs the additional parameters of mould quality evaluation.

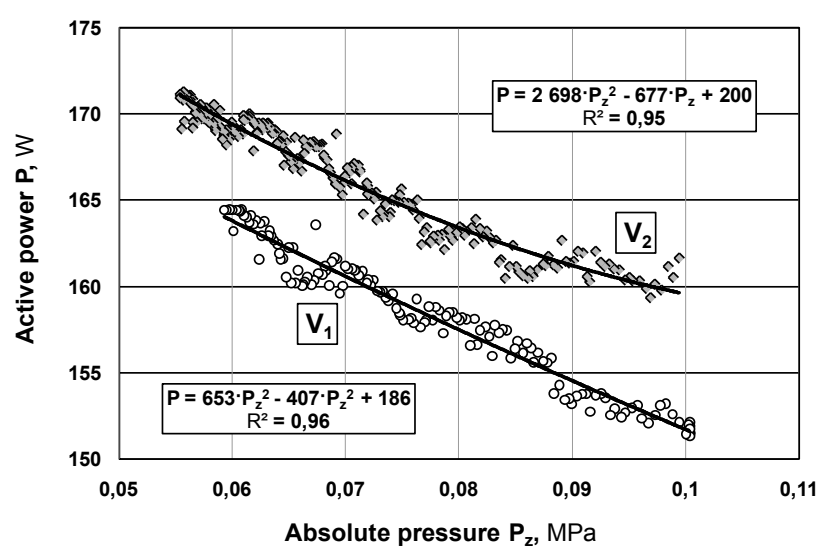

Fig. 8. Relation between active power- $\mathrm{P}$ and absolute pressure- $\mathrm{P}_{\mathrm{z}}$ in vacuum tank at the period of power growth. Vacuum pump No. 1, $\mathrm{V}_{1}, \mathrm{~V}_{2}$ - volumes of vacuum tanks. 


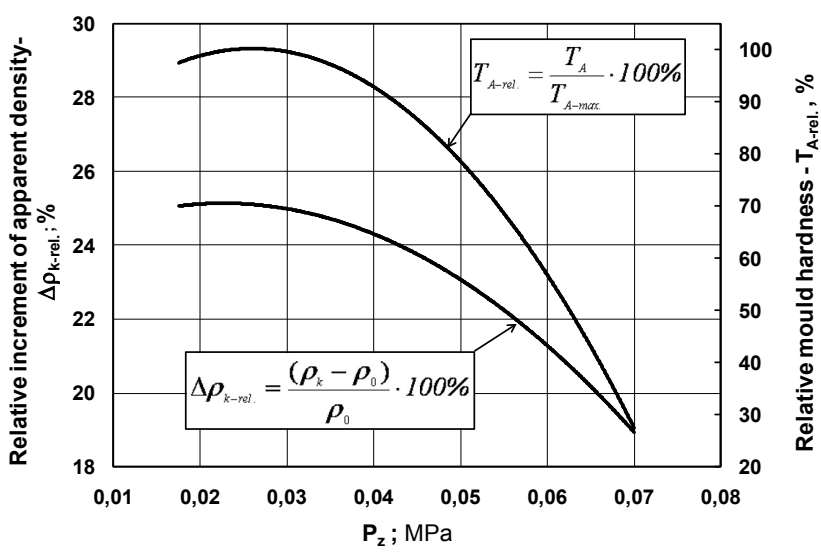

Fig. 9. Dependence between relative increment of apparent density of the mould- $\rho_{\mathrm{k} \text {-rel. }}$ or relative bottom surface hardness of the mould- $\mathbf{T}_{\mathbf{A} \text {-rel. }}$ and initial values of absolute pressure in vacuum tank- $\mathbf{P}_{\mathbf{z}}$. Vacuum assisted compaction

For example density distribution, density values in critical area of the mould etc. The used pumps have rather poor value of energy factor (about $248 \mathrm{~kJ} / \mathrm{m}^{3}$ )- see also Fig. 2 and Tab. 1. The instantaneous power and pressure measurement may be very useful in the proper choice of pump parameters as well as another parameters of vacuum installation (i.e. volume of the vacuum tank).

\section{Conclusions}

Parallel measurements of electric power parameters of foundry machine drive and important for machine operation quantities, especially the instantaneous values, are very useful in the proper choice of machine parameters. Measurements of electric power parameters are now much easier and more effective than other methods. The analysis of obtained data allows to evaluate the proper conditions of machine operation, not only in technological aspects but also in optimisation of energy demand. Further research work will merited to develop a mathematical model of an operation of vacuum moulding installation as well as suitable software for support the design process of such machine. Such measurements allow also for online control of processes and enable the diagnosis and identification of malfunctions of machines and installations in the process line.

\section{Acknowledgements}

The research was performed within the grant of MNiSW No. 11.11.170.318-6.

\section{References}

[1] Macioł, A., Wrona, R. \& Stawowy, A. (2010). An application of advanced information technology in foundry engineering. Archives of Foundry Engineering. 10(2), 83-88.
[2] Kukla, S. (2009). Total productive maintenance on example of automated foundry lines. Archives of Foundry Engineering. 9(3), 71- 74.

[3] Fedoryszyn, A. (2010). Quality stabilisation of synthetic sand containing bentonite in process lines. Archives of Foundry Engineering. 10(3), 143-148.

[4] Ziółkowski, E., Wrona, R. \& Smyksy, K. (2009). Some aspects of monitoring of foundry moulding sands preparation process. Archives of Metallurgy and Materials. 54(2), 399411.

[5] Fedoryszyn, A. \& Rudy, C. (2009). Operating characteristics of turbine mixers based on the analysis of power demand of the mixer's drive. Archives of Foundry Engineering. 9(1), $65-68$.

[6] Smyksy, K., Wrona, R. \& Ziółkowski, E. (2011). Application of a power quality analyser to the monitoring of sand preparation processes in foundry plants. Archives of Foundry Engineering. 11(4), 141-144.

[7] Wrona, R., Ziółkowski, E. \& Smyksy K. (2008). Monitoring of power demand of foundry machinery, using the example of paddle mixers. Archives of Foundry Engineering. 8(1), $177-182$.

[8] Ziółkowski, E. (2010). Monitoring of operations of supply system of electric-driven foundry devices. Archives of Foundry Engineering. 10(spec. 2), 169-172. (in Polish).

[9] Zöllig U.(2012): Energy-efficient vacuum for heat treatment and metallurgy. Pumps, Compressors and Process Components, 50-52

[10] Smyksy K., Ślazyk M. (2004): State of art analysis in vacuum technology : selected aspects of vacuum technology application in foundry devices. Proc. of VII ${ }^{\text {th }}$ Foundry Conference of Technical , 2004, pp.129-137. Nowa Sól. (in Polish)

[11] Wilk-Kołodziejczyk D., Regulski K. \& Dziaduś-Rudnicka J. \& Kluska-Nawarecka S. (2012). Overview of activities on the internet devoted to casting technology. Archives of Foundry Engineering. 12(2), 245-250.

[12] Folders of producers of vacuum pumps: Hydro-Vacuum S.A., Oerlikon Leybold Vacuum $\mathrm{GmbH}$

[13] Wrona, R., Ziółkowski E. \& Brzeziński M. \& Smyksy, K. \& Zyzak P. (2012). Applications of monitoring of electric power parameters to performance evaluation of a model vacuum-assisted moulding installations. Archives of Foundry Engineering. 12(2), 267-272.

[14] Brzeziński, M. (2010). Evaluation of vacuum assisted compaction processes of foundry moulding sand by theoretical and experimental methods. Archives of Metallurgy and Materials. 55(3), 763-770.

[15] Brzeziński, M., Wrona, R. (2011). Evaluation of automatic vacuum- assisted solution. Archives of Foundry Engineering. 11(1), 113-117.

[16] Ziółkowski, E. (2009). Investigation of power consumption by a laboratory roller mixer. Archives of Foundry Engineering. 9(1), 61-64.

[17] Smyksy, K., Wrona, R., \& Ziółkowski, E. (2010). Analysis of power demand signal in laboratory rotary mixer. Archives of Foundry Engineering. 10(2), 151-154. 